\title{
Perancangan Alat Irigasi Tetes SederhanaUntuk Tanaman Hias Sekolah Menengah Kejuruan Smk Negeri 4 Dumai Kelas 10 Mekanisasi Pertanian (Mp)
}

\author{
Trisna Mesra ${ }^{1}$, Melliana ${ }^{2}$ Fitra $^{3}$, Azmi $^{4}$, Novri Jenita Marbun ${ }^{5}$ \\ 1,2,3,4 Program Studi Teknik Industri Sekolah Tinggi Teknologi Dumai \\ Email: trisnamesra74@gmail.com¹․, Mellianna52@gmail.com, famukhtyfitra@gmail.com³ \\ azmi.omy@gmail.com ${ }^{4}$, ovibanjarnahor@gmail.com
}

\begin{abstract}
This Community Service Program partners with the Dumai City 4 State Vocational High School (SMK N 4 Dumai). This community service program is very important to implement because it will be able to help children to improve their knowledge and skills in the process of designing simple drip irrigation equipment for ornamental plants. So that vocational students can practice at school and at home and in the environment they are in. Where this drip irrigation tool will be used for ornamental plants in schools and at the homes of each student. With the implementation of this community service program, the community service team at the Dumai High School of Technology provides skills on how to make a simple drip irrigation device by utilizing materials and equipment around us and this is one of the provisions of knowledge for them when they have lived their lives later. . This knowledge can also be used as a skill to develop an entrepreneurial spirit to open a business world that can be used as a source of income.
\end{abstract}

Keywords: Design, Drip Irrigation, Ornamental Plants

\begin{abstract}
Abstrak
Program Pengabdian Masyarakat ini bermitra dengan Sekolah Menengah Kejuruan Negeri 4 Kota Dumai (SMK N 4 Dumai). Program pengabdian masyarakat ini sangat penting untuk dilaksanakan dikarenakan akan dapat membantu anak-anak untuk meningkatkan pengetahuan dan keterampilan proses perancangan alat irigasi tetes sederhana untuk tanaman hias. Sehingga siswa-siswi SMK bisa mempraktekkan di sekolah dan dirumah serta lingkungan mereka berada. Dimana alat irigasi tetes ini akan dapat dimanfaatkan untuk tanaman hias di sekolah dan di rumah siswa masing- masing. Dengan terlaksananya program pengabdian masyarakat ini, tim pelaksana pengabdian kepada masyarakat Sekolah Tinggi Teknologi Dumai memberikan skill tentang cara pembuatan alat irigasi tetes sederhana dengan memanfaatkan bahan bahan dan peralatan ada di sekitar kita dan ini merupakan salah satu bekal pengetahuan bagi mereka apabila mereka telah menjalani kehidupan nantinya. Pengetahuan ini juga bisa dijadikan suatu skill untuk mengembangkan jiwa kewirausahaan untuk membuka dunia usaha yang dapat dijadikan sebagai sumber penghasilan.
\end{abstract}

Kata Kunci: Perancangan, Irigasi Tetes, Tanaman Hias

\section{PENDAHULUAN}

Air merupakan suatu kebutuhan utama bagi tumbuh-tumbuhan termasuk tanaman budidaya. Namun keberadaan pada suatu lahan pertanaman perlu dipertimbangkan secara hati-hati, karena tidak semua jenis tanaman dapat tumbuh dengan kondisi air berlebih. Pada daerah dimana kondisi air berlebih, akan menyebabkan terjadinya gangguan pada tanaman, terutama perakaran tanaman. Akar tanaman tidak dapat berkembang dengan baik, dan pada akhirnya akartanaman akan busuk jika terus-menerus tergenang dalam air. Begitu juga bagi tanaman yang butuh dengan air terus menerus apabila tidak sesuai kebutuhan air dangan persediaan air yang ada dapat mengakibatkan layu pada tanaman bahkan bisa menjadi lebih cepat mati. Untuk mengatasi hal tersebut diperlukan suatu tindakan untuk mengatur kelebihan maupun kekurangan air tanaman. Pembuatan sistem drainase atau irigasi bukanlah suatu pekerjaan mudah, terutama bagi tanaman perkebunan, mengingat perkebunan merupakan suatu jenis usaha tani yang memiliki skala luas, sehingga 
untuk pembuatan sistem drainase dan pemberian air harus dilakukan dengan perhitungan yang matang dan cermat, dan harus melalui proses pembuatan desain.

Kebutuhan air irigasi perlu dianalisis, ini merupakan salah satu tahapan penting yang diperlukan dalam merancang dan mengelola sistem irigasi. Agar kebutuhan air irigasi dapat terpenuhi, maka dapat diperkirakan kebutuhan air irigasi perlu memperhatikan berbagai faktor yang berpengaruh terhadap kebutuhan dan ketersediaan (Mawardi, 2007), seperti :

a. Jenis dan sifat tanah

b. Macam dan jenis tanaman

c. Keadaan iklim

d. Keadaan topografi

e. Luas areal pertanaman

f. Kehilangan air selama pengaliran dan penyaluranya

Kebutuhan air tanaman didefinisikan sebagai jumlah air yang dibutuhkan oleh tanaman pada suatu periode untuk dapat tumbuh secara normal. Penggunaan air untuk kebutuhan tanaman dapat diprediksi dengan menghitung evapotranspirasi tanaman, yang besarnya dipengaruhi oleh jenis tanaman, umur tanaman dan faktor klimologi.

Melihat perkembangan budi daya tanaman hias yang marak dikembangkan di lingkungan rumah maupun di taman-taman sangat memerlukan kapasitas air yang sesuai supaya dapat berkembang dengan baik. Hal ini menjadi pemikiran bagi kita bagaimana menjaga kondisi air supaya tetap baik dan tanaman dapat tumbuh subur. Dengan kondisi ini perlu memiliki sarana dan prasana maupun tempat untuk melakukan penelitian supaya bisa di perhitungkan berapa kebutuhan air bagi tanaman dalam ruangan dan tanaman di luar ruangan.

Sekolah Menengah Kejuruan (SMK) Negeri 4 Dumai adalah satu-satunya sekolah kejuruan pertanian di Kota Dumai. Sekolah ini memiliki tiga kejuruan pertanian yaitu Agribisnis Tanaman Perkebunan (ATP), Mekanisasi Perkebunan (MP) dan Teknologi Hasil Perkebunan (ATP). SMK yang memiliki silabus Irigasi dan Drainase pada jurusan ATP dan MP sangat sesuai untuk mengembangkan keterampilan dasar siswa dalam aplikasi mata pelajaran tersebut. Mengingat materi pelajaran Irigasi dan drainasi yang diaplikasikan pada perkebunan dengan areal yang sangat luas dan harus membutuhkan irigasi dan drainase dalam kapasitas skala besar sangat menyulitkan bagi sekolah untuk menyediakan peralatan dan praktek dengan kebutuhan tersebut. Mengingat peralatan yang dimiliki oleh sekolah masih sangat minim untuk materi pelajaran irigasi ini sehingga kita membantu untuk merancang irigasi tetes sederhana yang dapat membantu meningkatkan kompetensi siswa dan dapat diaplikaskan pada siswa serta menjadi bahan praktek siswa. Berdasarkan latar belakang kondisi ini menantang kita untuk membantu merancang alat irigasi tetes dalam ruangan dengan peralatan sederhana dalam ruangan dan menjadi bahan pengabdian masyarakat yang dapat berfungsi untuk meningkatkan kompetensi siswa, sesuai dengan pengabdian yang dilakukan (Mesra, Melliana and Fitra, 2021) proses pembuatan kompos dari sampah organik di SMP Muhammadiyah Dumai. Memberikan skill tentang cara menumbuhkan motivasi kewirausahaan, proses pembuatan sabun dan proses merancang packaging produk sabun serta keterampilan atau mempraktekkan cara pembuatan sabun kepada anak-anak dipanti asuhan juga dilakukan (Mesra, Studi and Industri, 2019).

Irigasi adalah merupakan kegiatan pemberian air pada suatu lahan Pertanian yang bertujuan untuk menciptakan kondisi lembab pada daerah perakaran tanaman untuk memenuhi kebutuhan air bagi partumbuhan tanaman. Menurut (Saputro, 2013) irigasi merupakan kegiatan penyediaan dan pengaturan air untuk memenuhi 
kepentingan Pertanian dengan memanfaatkan air yang berasal dari air permukaan dan tanah. Menurut Linseley 1996 dalam (Vaughn, 2012) Pengairan adalah pemberian air kepada tanah untuk menunjang curah hujan yang tidak cukup agar tersedia lengas tanah bagi pertumbuhan tanaman. Penelitian yang dilakukan oleh (Susilowati, 2020) menunjukkan bahwa pola tanam dapat dioptimasi agar sesuai dengan ketersediaan air. Namun demikian, analisis lanjutan diperlukan pada berbagai skenario dengan berbasis indeks keandalan air agar selaras dengan konsep modernisasi irigasi. Menurut (Susilowati, Utaminingsih and Ginting, 2020) Optimasi rencana tanam dilakukan dengan memaksimalkan keandalan pemberian air irigasi. Irigasi selain bertujuan menyediakan air bagi pertumbuhan tanaman, juga memberikan manfaat lain seperti :

1. Mempermudah pekerjaan pengolahan tanah

2. Menekan pertumbuhan gulma, hama dan penyakit

3. Mengatur suhu tanah dan iklim mikromemberikan skill tentang cara menumbuhkan motivasi kewirausahaan, proses pembuatan sabun dan proses merancang packaging produk sabun serta keterampilan atau mempraktekkan cara pembuatan sabun kepada anak-anak dipanti asuhan sehingga anak-anak tersebut siap untuk berwirausaha setelah keluar dari panti asuhan serta bisa menjadi salah satu alternatif usaha yang akan dijalankan mereka

4. Memperbaiki kesuburan tanah

5. Menurunkan kadar garam dalam tanah

Jaringan irigasi adalah prasarana irigasi yang digunakan untuk mengatur dan menyalurkan mulai dari penyediaaan, pengambilan pembagian, pemberian dan penggunaan. Secara hirarki jaringan atau saluran irigasi dibagi menjadi tiga yakni saluran utama atau primer, saluran sekunder, saluran tersier dan saluran kuarter. Berdasarkan kelengkapan fasilitas, jaringan irigasi dapat dikelompokan menjadi 3 jenis yaitu :

1. Jaringan irigasi sederhana

2. Jaringan irigasi semi teknis

3. Jaringan irigasi tekhnis

Mengairi tanaman dalam irigasi adalah memberikan air pada tanaman untuk memenuhi kebutuhannya dan membuang kelebihan air. Jadi dengan cara ini pemberian air dan pembuangan air dapat dikendalikan baik jumlahnya maupun waktunya. Tujuan mengairi tanaman adalah untuk menyakinkan bahwa tanaman mendapatkan jumlah air yang cukup memadai pada zone perakarannya sehingga dapat memberikan produksi yang optimal. Pemberian air dapat memberikan efek tambahan yang positif maupun negatif.

Efek tambahan positif dari pemberian air adalah :

a. Air yang bersama nutrisi dapat menyuburkan tanah dan tanaman.

b. Air dapat mengatur suhu.

c. Memperbesar penyediaan air.

d. Mencuci garam-garam yang dapat meracuni tanaman

Efek tambahan yang negatif dari pemberian air adalah :

a. Jika terlalu banyak ada kemungkinan menutup rongga-rongga tanahsehingga udara tanah tidak ada.

b. Bila tanah digenangi dapat memungkinkan mengangkat garam-garam yang merugikan tanaman ke daerah perakaran tanaman.

Sistem irigasi tetes adalah salah satu alternatif dalam pemberian air pada tanaman (Ridoan, 2011). Sementara menurut (L, Elphyson and Nora, 2000) Rancangan irigasi tetes dapat diterapkan jika debit sumber air terjadi sampai 50\%. 
ABDINE: Jurnal Pengabdian Kepada Masyarakat Vol. 1, No.2, Desember 2021,Hal.168-177 p-ISSN 2798-2882, e-ISSN 2798-2890

\section{METODE}

Metode pelaksanaan pada pengabdian masyarakat (PPM) adalah memberikan pengetahuan tentang metoda metoda yang digunakan dalam perancangan alat irigasi tetes sederhana untuk tanaman hias, proses pembuatan dan praktek pembuatan alat irigasi tetes sederhana untuk tanaman hias di SMK Negeri 4 kota Dumai. Proses pelaksanaan pelatihan antara lain:

1. Pembuatan Modul yang berisi langkah-langkah proses pembuatan, material dan peralatan yang akan digunakan dalam merancang alat irigasi tetes sederhana.

2. Menyiapkan pelatan dan membeli bahan bahan yang akan digunakan pada saat pelatihan.

3. Pelaksanaan dan persiapan material serta peralatan yang digunakan dalam proses pelatihan dan membeli bahan-bahan sebagai bahan dasar untuk pembuatan kompos. Pelatihan dilaksanakan pada Sekolah Menengah Pertama praktek langsung perancangan dan pembuatan alat irigasi tetes sederhana untuk tanaman hias dengan melibatkan siswa kelas $\mathrm{X}$ mekanisasi Pertanian SMK Negeri 4.

\section{HASIL DAN PEMBAHASAN}

Pelaksanaan kegiatan PPM dengan judul " Perancangan Alat Irigasi Tetes Sederhana Untuk Tanaman Hias" diawali dengan memberikan penjelasan tentang proses merancang dan bahan serta alat yang digunakan dalam pembuatan alat irigasi tetes. Tahap selanjutnya adalah menyiapkan bahan dan alat yang digunakan dalam merancang irigasi tetes.

Peralatan pembuatan jaringan irigasi tetes khusus jaringan tertutup dipengaruhi oleh beberapa faktor seperti : besarnya wadah tanaman, keadaan ruangan, sumber air dan jenis tanaman hias. Secara umum beberapa peralatan yang diperlukan untuk membuat jaringan irigasi tetes pada ruangan tertertup untuk kegiatan tanaman hias antara lain :

a. Meteran (roll meter)

Spesifikasi: Panjang $10 \mathrm{~m}$ atau lebih yang fungsinya sebagai alat untuk bahan

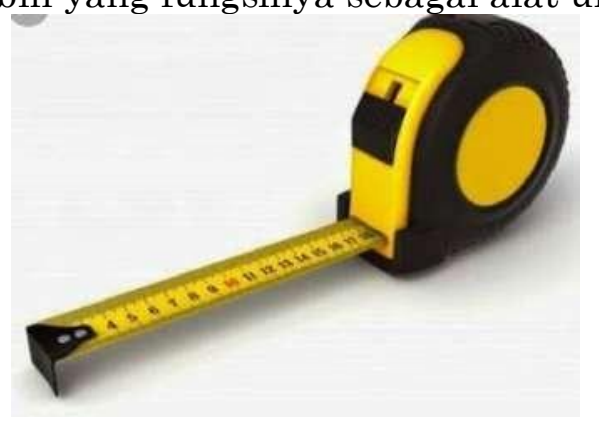

Gambar 1. Meteran

b. Pipa Paralon $3 / 4$

Spesifikasi : panjang $5 \mathrm{~m}$, yang berfungsi untuk membuat saluran irigasi 
ABDINE: Jurnal Pengabdian Kepada Masyarakat Vol. 1, No.2, Desember 2021,Hal.168-177 p-ISSN 2798-2882, e-ISSN 2798-2890

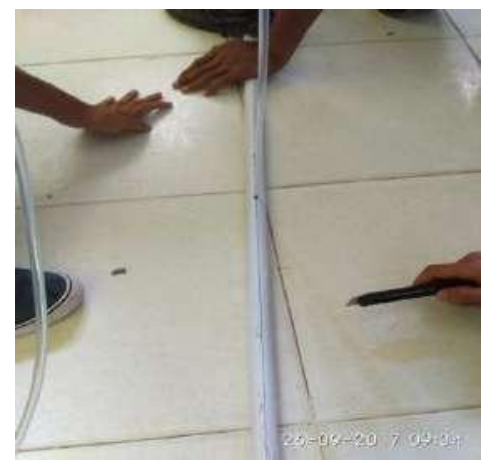

Gambar 2. Pipa Paralon

c. Selang Infus

Spesifikasi : ukuran Mikro dan Makro, yang berfungsi untuk mengatus kecepatan tetes air
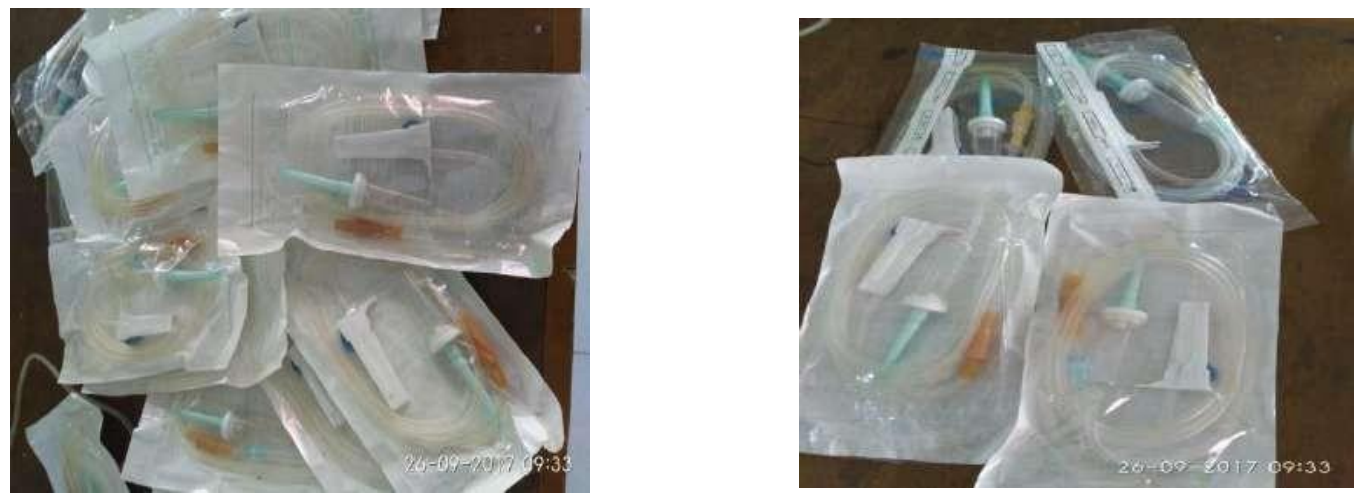

Gambar 3. Selang infus Micro

Gambar 4. Selang Infus Macro

d. Corong Air

Fungsi : untuk mengisi air ke Gallon air

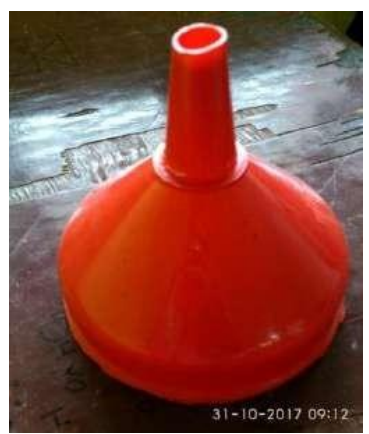

Gambar 5. Corong Air 
e. Tabung air (Gallon Air) Spesifikasi: kapasitas 50 Liter yang berfungsi untuk persediaan air

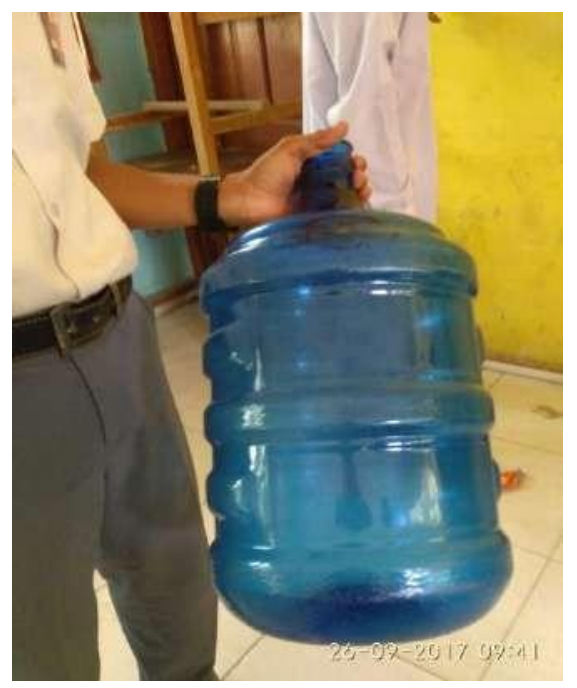

\section{Gambar 6. Tabung ( Gallon ) Air}

f. Selang 0,25"

Spesifikasi : panjang yang berfungsi untuk sambungan dari pipa paralon ke infus membuat saluranirigasi

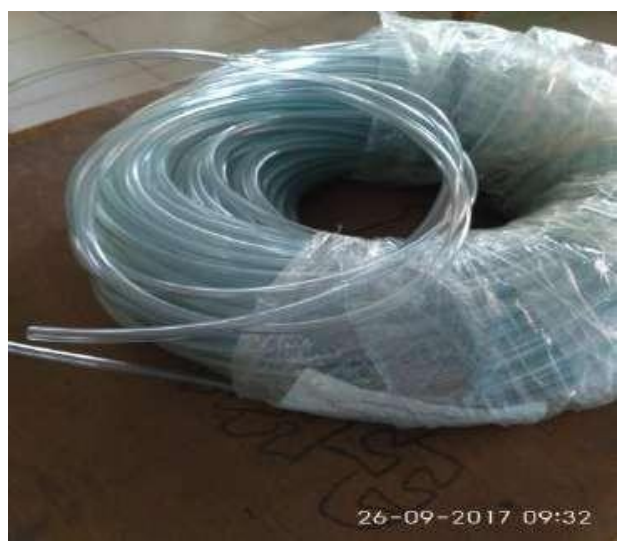

Gambar 7. Selang

g. Elbo $3 / 4$ yang berfungsi untuk membuat saluran irigasi

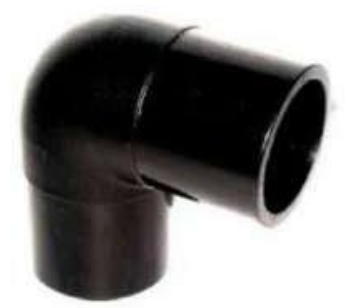

Gambar 8. Elbo 
h. Lem Pipa yang berfungsi untuk melem selang ke pipa

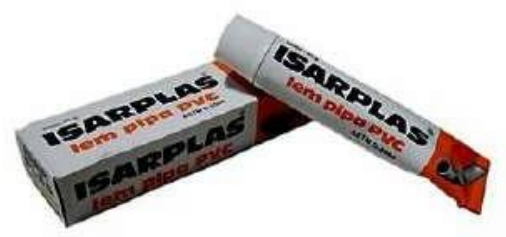

Gambar 9. Lem Pipa

i. Clem yang berfungsi untuk menahan/mengikat pipa pada dinding

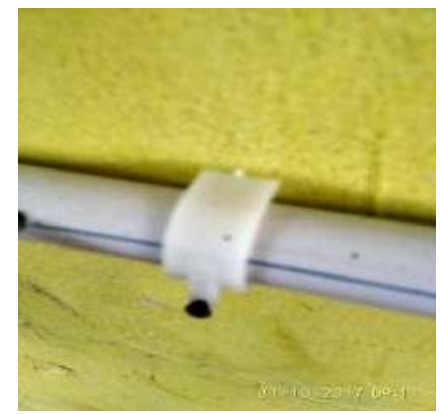

Gambar 10. Clem

J. Gunting yang berfungsi untuk menggunting panjangnya selang air yang dibutuhkan untuk infus $(20 \mathrm{~cm})$

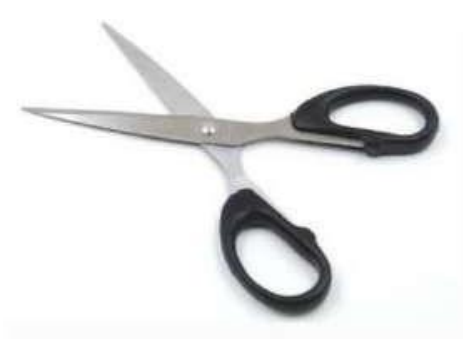

\section{Gambar 11. Gunting}

k. Piser dan Paku Beton yang berfungsi untuk memakukan pipa pada dinding

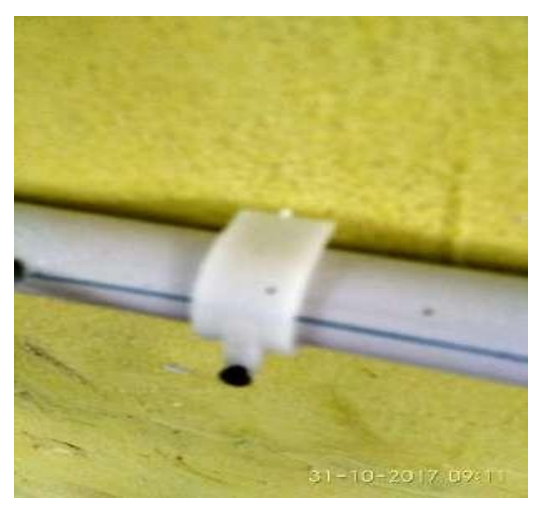




\section{Gambar 12. Piser dan Paku beton}

1. Pisau Cutter yang berfungsi untuk melobangi ppa sebesar selang untuk saluran air

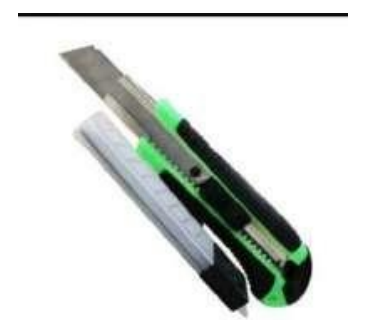

\section{Gambar 13. Pisai Cutter}

Tahap berikutnya adalah proses membuat alat irigasi tetes sederhana dengan memanfaatkan semua bahan yang telah disediakan dengan mengikuti langkah kerja berikut :

1. Ukur ketinggian tanaman hias dalam pot $(25 \mathrm{~cm})$

2. Ukur tinggi Pot dengan ketinggian tabung air $(150 \mathrm{~cm})$ dari tinggi potbunga

3. Ukur tinggi pipa paralon $(135 \mathrm{~cm})$ dari tinggi pot bunga

4. Ukur jarak setiap setiap pot $(50 \mathrm{~cm})$

5. Potong Pipa paralon sepanjang $30 \mathrm{~cm}$ dan $20 \mathrm{~cm}$ untuk membentuksambungan dari tabung air ke Pipa dengan memakai Elbo

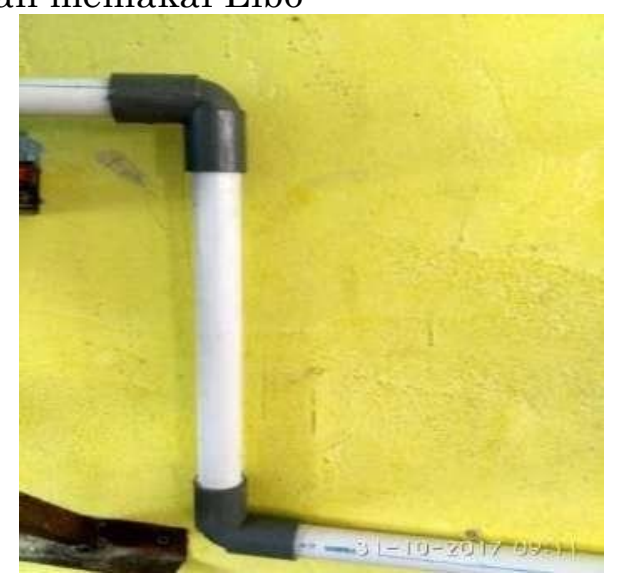

\section{Gambar 14. Sambungan dengan memakai Elbo}

6. Buat lobang pada Pipa paralon sebesar selang yang dibutuhkan untuk menyambung antara pipa paralon dengan selang infus dengan jarak $60 \mathrm{~cm}$ sebanyak 7 lobang 


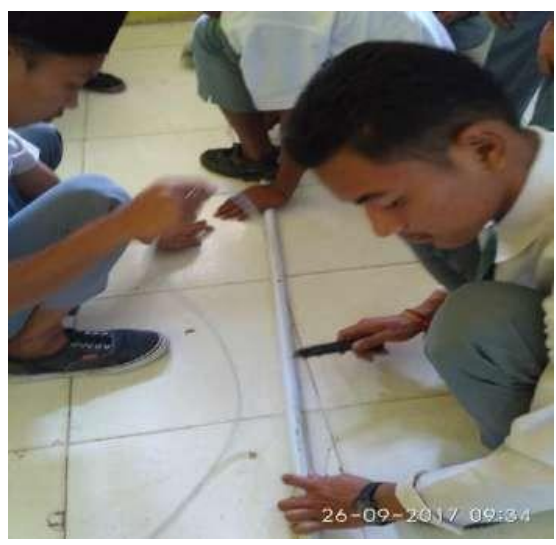

(a)

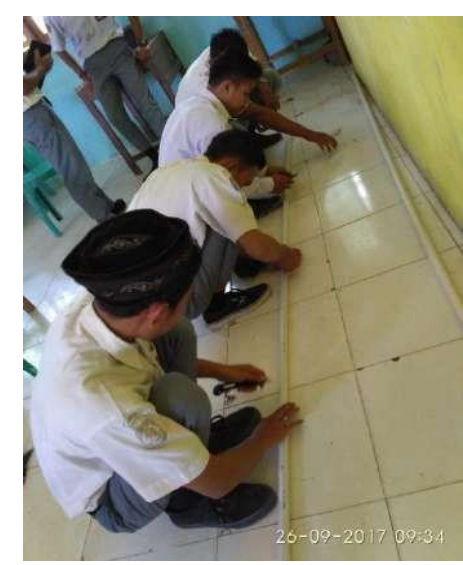

(b)

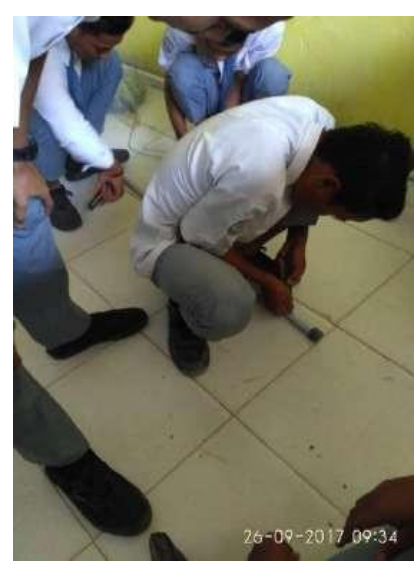

(c)

Gambar 15. Proses pengukuran dan pembuatanlobang pada Pipa, (a) Proses 1, (b) Proses 2, (c) Proses 3

7. Setelah Pipa dilobangi, pipa dipakukan ke dinding dengan ketinggian yangsudah ditentukan terlebih dahulu

8. Sambungkan Pipa dari Tabung air, Masukkan selang pada lobang pipadengan lem perekat, Ujung selang disambungkan kembali dengan infus

9. Lakukan Penyetelan infus (kecepatan tetes) pada saluran Pot bunga yangsudah tersedia

10. Siap untuk digunakan

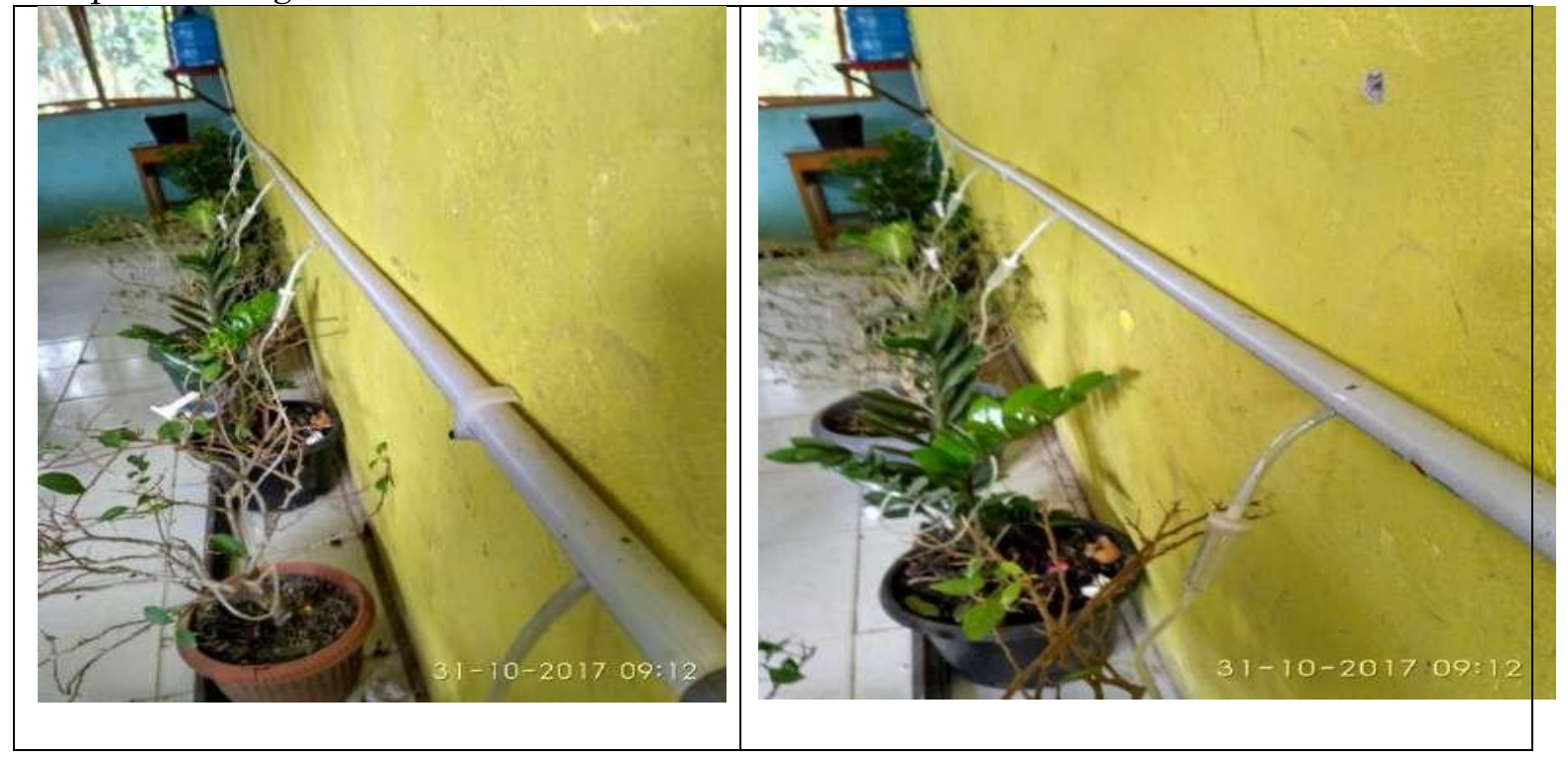

Gambar 16. Irigasi Tetes yang sudah siap digunakan

Rancangan alat irigasi tetes sederhana berhasil dibuat dengan harapan siswa siswi SMK Negeri 4 mendapatkan tambahan skill dan kompetensi keterampilan dalam menghasilkan suatu produk atau alat tepat guna yang dapat dimanfaatkan untuk tanaman hias maupun untuk tanaman holtikultura. Hal ini terbukti dari hasil penyebaran kuesioner yang mengukur tingkat pemahaman siswa siswi SMK Mekanisasi Pertanian sebanyak 90\% menyatakan sangat paham dan 10\% menyatakn 
cukup paham Diharapkan kedepannya siswa siswi dapat memanfaatkan keterampilan ini sebagai salah keahlian yang bisa menumbuhkan jiwa kewirausahaan untuk menghasilkan suatu produk yang dapat dipasarkan sehingga menghasilkan profit atau sebagai salah satu sumber pemasukan.

\section{KESIMPULAN}

Hasil analisis dan pengabdian yang dilakukan dapat memberikan suatu pengalaman dan ilmu yang langsung diterapkan bagi siswa di sekolah dan merupakan bahan masukan dan langsung bisa di praktekkan dan diaplikasikan di sekolah sesuai dengan kurikulum dan kompetensi anak didik. Diharapkan pada pengabdian berikutnya dilakukan penyuluhan tentang kelembaban air pada tanaman hias. Irigasi tetes ini baik digunakan bagi lingkungan rumah yang tertutup sehingga lebih mudah mengontrol ada dan menjaga kesuburan tanaman hias.

\section{DAFTAR PUSTAKA}

L, Elphyson, T. and Nora, H. (2000) 'Rancangan Jaringan Irigasi Tetes Untuk Tanaman Proyek Resinda, Karawang Design of Trickle Irrigation System for Peppers ( Capsicum annum var . longum L .) at Resinda Project, Karawang maupun dibawah permukaaan tanah melalui tetesan yang sinambung' dan ', 14(2).

Mawardi, E. (2007) Bangunan Irigasi. ALFABETA.

Mesra, T., Melliana, M. and Fitra, F. (2021) 'Pelatihan Proses Pembuatan Kompos Dari Sampah Organik Di Smp Muhammadiyah Dumai', ABDINE: Jurnal Pengabdian Masyarakat, 1(1), pp. 1-7. doi: 10.52072/abdine.v1i1.159.

Mesra, T., Studi, P. and Industri, T. (2019) 'Pelatihan Pembuatan Produk Sabun Pada Panti Asuhan Halimatuss ' diyah Muhammadiyah Untuk Meningkatkan Keterampilan Berwirausaha', pp. 38-42.

Ridoan, L. (2011) 'Pengaruh Proteksi Vitamin C Terhadap Kadar Ureum, Kreatinin dan Gambaran Histopatologis Ginjal Mencit yang Dipapar Plumbum', USU eRepository, III(1), pp. 63-74.

Saputro, K. (2013) Teknologi Pengairan Pertanian, Irigasi.

Susilowati, K. (2020) 'Analisis neraca air optimal irigasi untuk mendapatkan pola tanam optimal di daerah irigasi Ciliman', pp. 401-411.

Susilowati, Utaminingsih, W. and Ginting, S. (2020) 'Optimasi rencana tanam dan pemberian air irigasi menuju modernisasi irigasi di Daerah Irigasi Ciliman', Jurnal Irigasi, 15(2), p. 95. doi: 10.31028/ji.v15.i2.95-108.

Vaughn, H. (2012) Dasar dasar dan praktek irigasi. 